\title{
Perceptual organization of simple rhythmic sequences
}

\author{
IAN M. FRANKS and MICHAEL J. CANIC \\ University of British Columbia, Vancouver, British Columbia, Canada
}

\begin{abstract}
The present experiment focused on the perceptual organization of patterns whose structures could suggest the grouping of events into two intervals of equal duration. Subjects reproduced two series of patterns: in one, the suggested grouping intervals were initiated by external-world events, and in the other, they were not. The pattern structures in the latter series were not grouped as two intervals of equal duration. The patterns were instead grouped as two intervals of unequal duration, showing that the relative temporal positions of external-world events dominate in simple perceptual grouping.
\end{abstract}

A common feature among models of rhythm perception is that the relative timing of external-world events determines the selection of higher order (beat or metrical) grouping intervals (Longuet-Higgins \& Lee, 1982; Povel, 1981; Povel \& Essens, 1985). Typically, the higher order grouping interval is initiated by an external-world event.

As is often the case in music, however, a metrical context can be preserved even if the measure is not initiated by an external-world event. Apel (1972) reminds us that a beat may be external or internal to the subject. Franks and Canic (1991) found that well-practiced patterns could be accurately reproduced if the first higher order interval was divided into subintervals of equal duration and the second such interval was empty of external-world events. Sternberg, Knoll, and Zukofsky (1982, Experiment 12 ) showed that for the production of beat fractions, subjects were just as accurate when the start of production coincided with a given "beat" as when it began just after the given beat-that is, when the beat interval was not initiated by a subject-generated event.

For simple rhythmic patterns, do subjects perceive higher order groupings of equal duration when each higher order interval is not initiated by an external-world event? Do such patterns provide sufficient context for the perception of equal-duration higher order groupings? We investigate here patterns that are divisible into two intervals of equal duration. For all of the patterns, the first interval is divided into subintervals of equal duration. In one group of patterns, the second interval is initiated by an external-world event, the only event in that interval. In the other group, the second interval contains no external-world events.

This research was supported by a grant from the Natural Sciences and Engineering Research Council of Canada, awarded to I. M. Franks. Correspondence should be addressed to Ian M. Franks, Human Motor Performance Laboratory, 6801 University Blvd., University of British Columbia, Vancouver, BC, Canada V6T 1 Z1.
If the presented patterns are perceptually organized as two higher order intervals of equal duration, the accuracy of pattern reproduction would not be expected to differ between groups. In fact, the Gestalt principles of symmetry and regularity would support this organization of rhythmic patterns into higher order intervals of equal duration (see Jackendoff \& Lerdahl, 1981; West, Howell, \& Cross, 1985). However, Jackendoff and Lerdahl (1981) have proposed a "grouping preference rule" that strongly discourages single event groups. It is generally accepted that events at the beginning and the end of stimulus groups are psychologically accented (Fraisse, 1978, 1982; Povel \& Essens, 1985). Can beats that are internal to the perceiver occupy these positions?

\section{METHOD}

\section{Subjects}

Twenty-four male and female students from the University of British Columbia participated in the study as part of a course requirement. The subjects ranged in age from 21 to 33 years. A \$20 prize was offered to the subject who most accurately reproduced the response patterns.

\section{Apparatus}

The response apparatus consisted of a miniature speaker and a push button response key $(1.2 \mathrm{~cm}$ in diameter), which was located on the uppermost surface of a square metal frame along the edge closest to the subject. In addition, a green LED was located in the center of the frame. For these experiments, the LED served as the warning stimulus.

The response apparatus was interfaced with a Tecmar Labmaster data acquisition multifunction board, resident in an IBM XT microcomputer. This allowed the experimenter to run and control the experiment at the computer's keyboard. A complete description of the computer interface and apparatus can be found in Franks (1988).

A press on the response key completed an electronic circuit, signaling the beginning of a tap. The release of the key disengaged the circuit to mark the end of the tap. The output of the circuit was processed by the microcomputer to allow for storage and analysis of the temporal data from each trial. The data of interest in this experiment were the interresponse intervals (IRIs).

\section{Stimulus patterns}

The subjects were instructed to reproduce eight different stimulus patterns. Two pattern types were presented for each of four different pattern durations (see Table 1). All patterns could be divided into two in- 
Table 1

Stimulus Patterns for Experiment 1

\begin{tabular}{|c|c|c|c|}
\hline $\begin{array}{l}\text { Pattern } \\
\text { Type }\end{array}$ & Duration & Pattern Representation & Ratio \\
\hline $\begin{array}{l}\mathbf{X} \\
\mathbf{E}\end{array}$ & $1,200 \mathrm{msec}$ & $\begin{array}{l}1 . . . .1 \ldots . . \\
1 . .1 . . \ldots . .\end{array}$ & $1: 1: 2$ \\
\hline $\begin{array}{l}\mathbf{X} \\
\mathbf{E}\end{array}$ & $\underset{n}{1,800 \mathrm{msec}}$ & $\begin{array}{l}\mid . / . . / . .1 \ldots \ldots \ldots \\
\mid . . / . .1 . \ldots \ldots \ldots .\end{array}$ & $1: 1: 1: 3$ \\
\hline $\begin{array}{l}\mathbf{X} \\
\mathbf{E}\end{array}$ & $\underset{n}{2,400 \mathrm{msec}}$ & $\begin{array}{l}\mid . / . . . . / . . \ldots \ldots \ldots \ldots \\
\mid . . / . . . / \ldots \ldots \ldots \ldots \ldots\end{array}$ & $1: 1: 1: 1: 4$ \\
\hline $\begin{array}{l}\mathbf{X} \\
\mathbf{E}\end{array}$ & 3,000 msec & 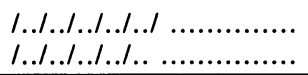 & $1: 1: 1: 1: 1: 5$ \\
\hline
\end{tabular}

Note-“/" represents an external-world event (100 msec). "." represents a silent interval $(100 \mathrm{msec})$. " $X$ " represents patterns in which both intervals are initiated by an external-world event. " $E$ " represents patterns in which the second interval is empty. For the sake of clarity, breaks have been inserted, artificially dividing each pattern into intervals of equal duration.

tervals of equal duration, with the first interval further divided into equal-duration subintervals. For half of the patterns, the second interval was initiated with an external-world event (X-type patterns); the other half contained no external-world event (E-type patterns). The physical characteristics of the tones were the same for both stimulus and response.

\section{Procedure}

The subjects were seated at a table and instructed about the nature of the study. A demonstration of the procedure was viewed. The time line for stimulus presensentation can be seen in Figure 1. The stimulus patterns are shown in Table 1 . The subjects listened to 20 cycles of each stimulus pattern, and then, following a warning tone, they reproduced each pattern cyclically until keypressing no longer generated response tones (after 20 cycles).

One trial was performed for each stimulus pattern. The order of presentation across subjects was determined by a balanced Latin square design. Reproduction of all eight stimulus patterns concluded the study. The task was to reproduce the timing of each stimulus pattern as accurately as possible.

\section{Analysis}

The fundamental unit of comparison was the IRI. Relative measures of the shortest temporal intervals $(300 \mathrm{msec}$ ) to longest temporal intervals $(600-1,500 \mathrm{msec})$ were not possible for the patterns with the empty second interval, since there was no external-world event to act as a marker in time. As a result, patterns of the same type were compared with respect to: (1) total pattern duration; (2) the IRI profiles across the shorter durations common to each pattern; and (3) interindividual variability in the reproduction of shorter IRIs and total pattern durations.

Total durations for X-type and E-type patterns were compared by calculating a proportional error score equal to $(x-c) / c$, where $x$ is the reproduced pattern duration and $c$ is the criterion duration (i.e., 1,200, $1,800,2,400$, or $3,000 \mathrm{msec}$ ).

\section{RESULTS}

\section{Interval Data}

Means and standard deviations for the reproduced interval data are shown in Table 2. An ANOVA was performed on the proportional error scores for the total pattern durations; this allowed comparisons across patterns of different total durations. A significant difference between X-type and E-type patterns was revealed $[F(1,23)$ $=6.66, p=.017]$ : the $\mathrm{X}$-type patterns were reproduced more accurately. There were no reliable proportional error differences across total pattern durations, nor were there for the interaction of duration and pattern type. As can be seen in Table 2, the superior performance of $\mathrm{X}$ type patterns was not consistent for all pattern durations. A subsequent ANOVA was undertaken to see whether this inconsistency might be attributed to an additional factor; specifically, patterns with an even number of shorter durations in the first interval generally appeared to be reproduced better than those with an odd number of such durations. This insight was supported $[F(1,23)=6.70$, $p=.016]$.

TIME LINE FOR STIMULUS PRESENTATION AND RESPONSE PRODUCTION

( e.g. pattern /...../.... )

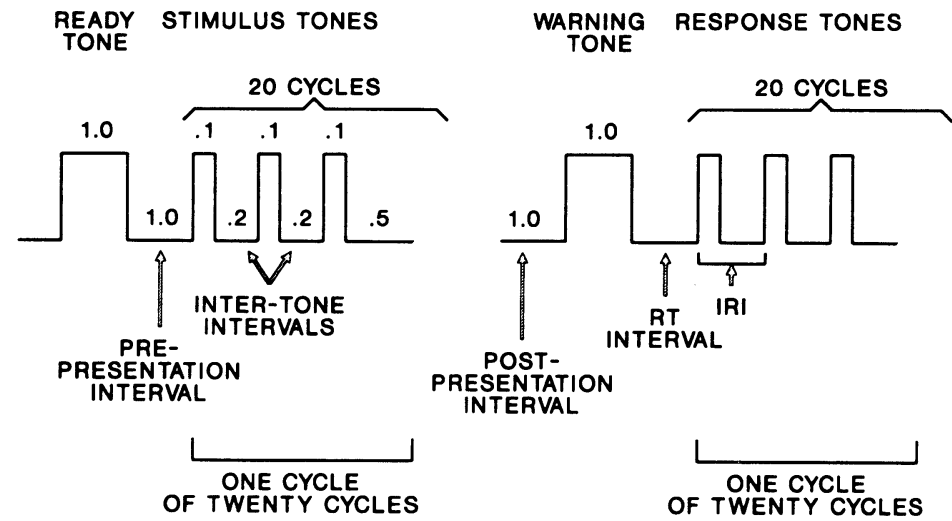

-all times in seconds

Figure 1. Time line for stimulus presentation and response production. 
Table 2

Mean Interresponse Interval (IRI) and Total Pattern Durations (in Milliseconds) and Corresponding SDs as a Function of Serial Position for Each Pattern

\begin{tabular}{|c|c|c|c|c|c|c|c|c|c|c|c|c|c|c|c|}
\hline \multirow{3}{*}{$\begin{array}{c}\text { Pattern } \\
\text { Type }\end{array}$} & \multirow[b]{3}{*}{ Duration } & \multicolumn{12}{|c|}{ IRI Serial Position } & & \\
\hline & & \multicolumn{2}{|c|}{1} & \multicolumn{2}{|c|}{2} & \multicolumn{2}{|c|}{3} & \multicolumn{2}{|c|}{4} & \multicolumn{2}{|c|}{5} & \multicolumn{2}{|c|}{ Last } & \multicolumn{2}{|c|}{ Total } \\
\hline & & $M$ & $S D$ & $M$ & $S D$ & $M$ & $S D$ & $M$ & $S D$ & $M$ & $S D$ & $M$ & $\overline{S D}$ & $M$ & $S D$ \\
\hline $\begin{array}{l}X \\
E\end{array}$ & 1,200 & $\begin{array}{l}285 \\
299\end{array}$ & $\begin{array}{l}12 \\
39\end{array}$ & 294 & 14 & & & & & & & $\begin{array}{l}608 \\
824\end{array}$ & $\begin{array}{c}36 \\
91\end{array}$ & $\begin{array}{l}1,187 \\
1,123\end{array}$ & $\begin{array}{l}38 \\
85\end{array}$ \\
\hline $\begin{array}{l}\mathbf{X} \\
\mathrm{E}\end{array}$ & 1,800 & $\begin{array}{l}292 \\
295\end{array}$ & $\begin{array}{l}24 \\
38\end{array}$ & $\begin{array}{l}290 \\
305\end{array}$ & $\begin{array}{l}18 \\
38\end{array}$ & 289 & 13 & & & & & $\begin{array}{r}849 \\
1,125\end{array}$ & $\begin{array}{l}113 \\
233\end{array}$ & $\begin{array}{l}1,720 \\
1,725\end{array}$ & $\begin{array}{l}119 \\
161\end{array}$ \\
\hline $\begin{array}{l}\mathrm{X} \\
\mathrm{E}\end{array}$ & 2,400 & $\begin{array}{l}292 \\
296\end{array}$ & $\begin{array}{l}23 \\
46\end{array}$ & $\begin{array}{l}294 \\
293\end{array}$ & $\begin{array}{l}26 \\
34\end{array}$ & $\begin{array}{l}288 \\
299\end{array}$ & $\begin{array}{l}21 \\
43\end{array}$ & 300 & 10 & & & $\begin{array}{l}1,134 \\
1,319\end{array}$ & $\begin{array}{l}165 \\
230\end{array}$ & $\begin{array}{l}2,308 \\
2,207\end{array}$ & $\begin{array}{l}174 \\
240\end{array}$ \\
\hline $\begin{array}{l}\mathbf{X} \\
\mathbf{E}\end{array}$ & 3,000 & $\begin{array}{l}296 \\
299 \\
\end{array}$ & $\begin{array}{l}36 \\
49 \\
\end{array}$ & $\begin{array}{l}296 \\
293 \\
\end{array}$ & $\begin{array}{l}31 \\
41\end{array}$ & $\begin{array}{l}291 \\
286\end{array}$ & $\begin{array}{l}27 \\
34\end{array}$ & $\begin{array}{l}295 \\
307\end{array}$ & $\begin{array}{l}30 \\
41 \\
\end{array}$ & 299 & 14 & $\begin{array}{l}1,339 \\
1,605\end{array}$ & $\begin{array}{l}263 \\
278\end{array}$ & $\begin{array}{l}2,816 \\
2,790\end{array}$ & $\begin{array}{l}259 \\
310\end{array}$ \\
\hline
\end{tabular}

Note- " $X$ " represents patterns in which both subintervals are initiated by an external-world event. " $E$ " represents patterns in which the second subinterval is empty.

The duration profiles for the shorter IRIs (i.e., serial position trends) were compared between pattern types at each duration. A significant interaction (serial position and pattern type) was found for the four shorter intervals common to the 3,000-msec patterns $[F(3,69)=13.04, p<$ $.001]$, for the three intervals common to the $2,400-\mathrm{msec}$ patterns $[F(2,46)=4.54, p=.023]$, and for the two intervals common to the 1,800 -msec patterns $[F(1,23)=$ $6.28, p=.020]$. A comparison of the single shorter invervals common to the 1,200 -msec patterns failed to reach statistical significance $[F(1,23)=3.63, p=.070]$. No main effects of pattern type were uncovered, indicating that differences in performance were largely attributable to reproduction of the largest temporal interval. Only one effect of serial position was found for the 3,000-msec patterns $[F(3,69)=14.61, p<.001]$. For all $p$ values reported here, the Greenhouse-Geisser epsilon factor was used for degrees of freedom adjustment.

The ratios of each shorter interval (common to both pattern types) to the total pattern duration are shown in $\mathrm{Ta}$ ble 3 . These data highlight the finding that even when the total duration of the X-type patterns was reduced, the relative timing of intervals within each pattern was well maintained.

Table 3

Mean Ratio of Shorter Temporal Intervals to Longer Temporal Intervals as a Function of Pattern Type

\begin{tabular}{ccccccc}
\hline \multirow{2}{*}{$\begin{array}{c}\text { Pattern } \\
\text { Type }\end{array}$} & Duration & $\mathrm{S}_{1} / \mathrm{T}$ & $\mathrm{S}_{2} / \mathrm{T}$ & $\mathrm{S}_{3} / \mathrm{T}$ & $\mathrm{S}_{4} / \mathrm{T}$ & Criterion \\
\cline { 3 - 6 } Ratio \\
\hline $\mathrm{X}$ & 1,200 & .240 & & & .250 & \\
$\mathrm{E}$ & & .266 & & &. & \\
$\mathrm{X}$ & 1,800 & .170 & .169 & & & .167 \\
$\mathrm{E}$ & & .171 & .177 & & & \\
$\mathrm{X}$ & 2,400 & .127 & .127 & .125 & & .125 \\
$\mathrm{E}$ & & .134 & .133 & .135 & & \\
$\mathrm{X}$ & 3,000 & .105 & .105 & .103 & .105 & .100 \\
$\mathrm{E}$ & & .107 & .105 & .102 & .110 & .100 \\
\hline
\end{tabular}

Note- $S_{n} / T$ represents the ratio of the $n$th shorter temporal interval $(300 \mathrm{msec})$ to the total pattern duration.
Four separate ANOVAs were conducted to contrast the durations of the first and second beat intervals within the $\mathrm{X}$-type patterns. The second interval duration (shown under the heading "Last" in Table 2) is less than the first interval duration (calculated by subtracting "Last" from " $T$ ") in all cases except for the 1,200-msec pattern (see Table 2). However, these findings were not statistically significant.

\section{DISCUSSION}

The primary purpose of this study was to determine whether the minimal context provided by the E-type patterns would lead subjects to perceive two higher order intervals of equal duration. Three pieces of evidence suggest that this was not the case. First, the reproduction of total pattern durations was better for the X-type than for the E-type patterns. Second, the intersubject variability of the duration profiles for the shorter IRIs and each of the four total durations was greater for the E-type patterns than for the X-type patterns (see Table 2). This indicates that subjects, as a whole, were not perceiving and reproducing the E-type patterns in a consistent way. This finding is at odds with an earlier study that we have conducted (Franks \& Canic, 1991). However, the subjects in that study were involved in considerably more learning trials than the subjects in the present study were.

There was no main effect of pattern type for the reproduction of shorter IRIs (just the interaction noted above). This indicates that differences were attributable almost entirely to the reproduction of the longer IRIs.

If the E-type patterns were not organized as two intervals of equal duration, how were they organized? The duration profiles of the shorter IRIs may give us a clue here. For each E-type pattern with multiple shorter IRIs, the last IRI is the longest in duration. If we consider again that intervals that end perceptual groups are accented, it appears that all the short intervals are grouped together, and that the longer interval is treated as a distinct unit. The E-type patterns are likely organized as two higher order intervals of different durations. The principles that would suggest the organization of two equal-duration intervals are overriden by the lack of contextual cues. This explanation is supported by the observation that equivalent longer interstimulus intervals (ISIs) (e.g., $900 \mathrm{msec}$ for the X-type 1,800-msec patterns and the E-type 1,200-msec pattern) were always better reproduced in the X-type patterns. In the presence of a metrical (equal interval) context, reproduction of a longer interval is degraded less than when it occurs in the absence of such a context-when it occurs in isolation.

Why should the error always be in the direction of reducing the longer interval? There is some evidence that an "indifferent interval" (an interval of time that is neither overestimated nor underestimated) exists around $700 \mathrm{msec}$ (Coren, Porac, \& Ward, 1984; but cf. Poppel, 1978, and Woodrow, 1951). Longer intervals are underestimated, and shorter intervals are overestimated. In the results presented here, the longer 
ISIs are underestimated in every case, with the exception of the 600 -msec ISI in one X-type pattern.

Of course, there are alternative explanations. First, Essens and Povel (1985) found that nonmetrical patterns are reproduced so that the ratio of longer to shorter durations approaches $2: 1$. A further explanation is found in Helson's (1964) adaptation level theory. Applied to the present study, the central idea is that stimuli are organized so that their differences along a common dimension are reduced. Consistent with both explanations, in patterns with multiple shorter IRIs, the longer IRI will be reduced.

\section{REFERENCES}

APEL, W. (1972). Harvard dictionary of music (2nd ed.). Cambridge, MA: Harvard University Press.

Coren, S., Porac, C., \& WARD, L. M. (1984). Sensation and perception (2nd ed.). Orlando, FL: Academic Press.

Essens, P. J., \& Povel, D.-J. (1985). Metrical and nonmetrical representations of temporal patterns. Perception \& Psychophysics, 37, 1-7.

Fraisse, P. (1978). Time and rhythm perception. In E. C. Carterette \& M. P. Friedman (Eds.), Handbook of perception (Vol. 8, pp. 203254). New York: Academic Press.

Fraisse, P. (1982). Rhythm and tempo. In D. Deutsch (Ed.), The psychology of music (pp. 149-180). New York: Academic Press.

FranKS, I. M. (1988). A method for investigating the sequential ordering of simple movement patterns: An IBM-based application using the Tecmar Labmaster. Behavior Research Methods, Instruments, \& Computers, 20, 298-306.
Franks, I. M., \& CANIC, M. J. (1991). The cognitive organization of simple rhythmic patterns. Journal of Human Movement Studies, 20, 149-162.

HeLson, H. (1964). Adaptation level theory: An experimental systematic approach to behavior. New York: Harper \& Row.

JACKENDOFF, R., \& LERDAHL, F. (1981). Generative music theory and its relation to psychology. Journal of Music Theory, 25, 45-90.

LONGUET-Higgins, H. C., \& LEE, C. S. (1982). The perception of musical rhythms. Perception, 11, 115-128.

PopPEL, E. (1978). Time perception. In R. Held, W. Leibowitz, \& H. L. Teuber (Eds.), Handbook of sensory physiology: Vol. 8. Perception (pp. 713-729). Berlin: Springer-Verlag.

Povel, D. J. (1981). Internal representation of simple temporal patterns. Journal of Experimental Psychology: Human Perception \& Performance, 7, 3-18.

Povel, D. J., \& Essens, P. (1985). Perception of temporal patterns. Music Perception, 2, 411-140.

Sternberg, S., Knoll, R. L., \& Zukofsky, P. (1982). Timing by skilled musicians. In D. Deutsch (Ed.), The psychology of music (pp. 181-239). New York: Academic Press.

West, R. Howell, P., \& Cross, I. (1985). Modelling perceived musical structure. In P. Howell, I. Cross, \& R. West (Eds.), Musical structure and cognition (pp. 21-52). London: Academic Press.

WoOdrow, H. (1951). Time perception. In S. S. Stevens (Ed.), Handbook of experimental psychology (pp. 1224-1236). New York: Wiley.

(Manuscript received February 28, 1992.) 